\title{
La dignidad de la persona humana $y$ el consentimiento informado
}

\author{
Luz Monge Talavera
}

\section{Introducción}

El derecho a la dignidad, invocado como el fundamento y justificación de la protección de los derechos de la persona, es considerado actualmente como el principio universal del derecho (Seriaux, 1997). El principio, que no forma parte de la clasificación iusprivatista de los derechos de la personalidad ${ }^{1}$-calificados como derechos inherentes a ella y, por lo tanto, inalienables, indisponibles e imprescriptibles-, se advierte ausente de la legislación civil y particularmente del Código Civil de 1984. Sin embargo, cabe notar que, desde la perspectiva del derecho positivo comparado, la dignidad de la persona humana pasó inadvertida hasta hace no mucho. No apareció como concepto jurídico en las codificaciones del siglo XIX. Jurídicamente, estamos frente a un concepto nuevo (Edelman, 1997, p. 185).

Los primeros textos legislativos que hacen referencia expresa al principio de la dignidad de la persona humana son los instrumentos internacionales de protección de los derechos humanos. Posteriormente a su consagración en ellos, y especialmente a partir de la segunda mitad

1 Tradicionalmente, el reconocimiento y la protección de los derechos primordiales de la persona se centraban en el concepto de libertad e igualdad. 
del siglo XIX, los Estados incluyen progresivamente este principio en su derecho positivo. Algunos países lo hacen en sus Códigos Civiles; otros elevan su protección y respeto al rango constitucional.

Razones históricas explican, sin lugar a dudas, que la República Federal Alemana haya consagrado desde 1949, en el artículo primero de la Ley Fundamental (1949), que "la dignidad del ser humano es intangible". Agrega, además, que "todos los poderes públicos tienen la obligación de respetarla y protegerla". Recientemente, en 1994, Francia prevé en el artículo 16 del Código Civil que "la ley garantiza la primacía de la persona, prohíbe todo atentado contra su dignidad y garantiza el respeto del ser humano desde el inicio de su vida". En el Perú, la Constitución Política de 1993 inicia su articulado consagrando en forma de declaración de principios que "la defensa de la persona humana y el respeto de su dignidad son el fin supremo de la sociedad y del Estado" 2 . Queda, sin embargo, remarcar que la noción misma de dignidad de la persona humana, en el plano jurídico, aparece indefinida.

El principio de la dignidad del ser humano, en cuanto cimiento de todos los derechos humanos, garantiza, desde la perspectiva constitucional, los derechos fundamentales de la persona frente a cualquier arbitrariedad de los poderes públicos. Paralelamente, en el ámbito del derecho privado, la dignidad inherente a la persona humana es también el criterio que preside la protección y el respeto de los derechos de la personalidad en las relaciones entre particulares. No podemos ignorar que -a pesar de que su protección se invoque en el ámbito civil- los derechos de la personalidad no son diferentes de los derechos fundamentales.

Actualmente, la consagración de la dignidad del ser humano se yergue como el principio de los principios que justifica la protección de la persona humana. Si bien su alcance universal fue la respuesta de la comunidad internacional a los crímenes cometidos bajo el régimen nazi, es pertinente destacar que la actualidad del principio se debe incontestablemente a los extraordinarios progresos de la biomedicina.

2 Según Landa (2002), la Constitución ha incorporado a la dignidad de la persona humana como un concepto jurídico abierto. El autor sostiene que la dignidad es la razón de ser, fin y límite de los derechos fundamentales (p. 129). 


\section{El principio de la dignidad del ser humano}

La palabra dignidad es una expresión que presenta diversos significados. No solo se trata de una construcción filosófica, también tiene un sentido social, un sentido moral $\mathrm{y}$, además, revela un estado de la persona (Verspieren, 2014). En el lenguaje corriente, el término se usa para resaltar los méritos personales o la función que desempeña una persona (cargo o empleo honorífico y de autoridad), como cuando habla de dignatarios. Por otro lado, en su sentido moral, evoca valor o decencia. Se vincula también al comportamiento ideal de una persona, al dominio de sí mismo, a su proceder conforme a los cánones sociales. El decoro de las personas en la manera de comportarse es calificado como un comportamiento digno.

En el plano jurídico y ético, la noción de dignidad parece revestir contornos no solo poco definidos, sino también vagos y difíciles de caracterizar. Se la invoca tanto para justificar como para rechazar posiciones controvertidas. Tratándose de la eutanasia, por ejemplo, aquellos que están a favor hablan del derecho a morir dignamente; los que se oponen califican la eutanasia como un atentado contra la dignidad de la persona humana. En cuanto al aborto, la dignidad humana del feto es erigida para rechazar la interrupción voluntaria de la gestación. En el otro extremo, se señala que imponer a una mujer un embarazo no deseado vulnera el respeto de su autonomía y la protección de su dignidad.

Lo cierto es que, a pesar de la importancia progresiva que el término ha adquirido en el ámbito legislativo, no existe consenso respecto a su significado. En medio de posiciones controvertidas, creemos que emerge claramente la indisoluble unidad de los términos dignidad y humanidad. La noción se encuentra estrechamente vinculada a la célebre fórmula de Kant, según la cual "la persona humana es un fin en sí misma y jamás un medio destinado a satisfacer intereses ajenos". La dignidad inherente a su naturaleza humana y racional la coloca por encima de todo, impidiendo que pueda ser instrumentalizada (por otra persona o por sí misma). El principio pone de manifiesto que el ser humano no puede ser reducido a la calidad de objeto porque es, y encarna, al sujeto de derecho por antonomasia. La palabra dignidad alude, entonces, al respeto que se debe a todo ser humano por el hecho de ser humano. Estrictamente, no se trata de un derecho subjetivo.

A partir de esta idea, se puede decir que la dignidad es una calidad inherente a todos y cada uno de los seres humanos sin distingo étnico, 
de género, de religión, de opinión o de creencias. Es posible catalogarla como un distintivo de la condición humana. En ese sentido, existe unanimidad en el hecho de que la dignidad no es estrictamente un derecho fundamental, sino más bien la base misma de los derechos fundamentales. La dignidad, como cualidad que identifica la pertenencia a la humanidad, se ubica en un plano superior a los derechos humanos. Se trata -según el profesor Edelman (1997)- de un "derecho natural supra-nacional". Para el profesor Habermas (2010), la dignidad "constituye la 'fuente' moral de la que todos los derechos fundamentales derivan su sustento" (p. 10).

\section{El respeto de la dignidad del ser humano es el fundamento de los instrumentos que garantizan la protección de los derechos humanos}

Es tan significativo para la condición humana que la persona sea siempre tratada como un sujeto, y nunca como un objeto, que todos los textos internacionales de protección de derechos humanos han erigido el respeto de la dignidad de la persona humana y el respeto de su autonomía como principios inquebrantables y de alcance universal. Ambos se presentan como un presupuesto indefectible para la coexistencia social pacífica.

Desde 1948, la Declaración Universal de los Derechos Humanos proclama en su preámbulo "el reconocimiento de la dignidad intrínseca de todos los miembros de la familia humana". Casi cincuenta años después, en 1997, el principio de la dignidad aparece en forma recurrente en la Declaración Universal sobre el Genoma Humano y los Derechos Humanos de la UNESCO (1997), la cual, luego de elevar -en sentido simbólico- el genoma humano al rango de patrimonio de la humanidad, coloca el respeto de la dignidad de la persona humana, los derechos humanos y las libertades fundamentales como el fundamento de los principios que enmarcan los progresos de la biomedicina. Así se declara: "Cada individuo tiene derecho al respeto de su dignidad y derechos, cualesquiera que sean sus características genéticas" (artículo 2).

Posteriormente, en 2005, cuando la comunidad internacional tuvo que aportar una respuesta universal a los dilemas éticos planteados por los progresos de la ciencia y la tecnología, la Declaración Universal sobre Bioética y Derechos Humanos de la UNESCO (2005) precisó que en las decisiones o prácticas ejecutadas en este dominio "se habrán de 
respetar plenamente la dignidad humana, los derechos humanos y las libertades fundamentales" (artículo 3).

A nivel regional, la Convención Europea sobre los Derechos Humanos y la Biomedicina ${ }^{3}$, aprobada en $1997^{4}$ (Convención de Oviedo), es el primer instrumento internacional dotado de fuerza obligatoria destinado a proteger la dignidad e identidad del ser humano frente a los progresos de la biología y la medicina. La Convención de Oviedo (1997), considerada como el referente legislativo mayor en este dominio, consagra la idea de que "el interés y el bienestar del ser humano deben primar frente al interés de la ciencia y de la sociedad".

Por su parte, la Carta de los Derechos Fundamentales de la Unión Europea (2000) señala en su preámbulo que los pueblos de Europa, al crear una unión entre sí, "sitúan a la persona en el centro de su actuación"; luego proclama en su artículo primero que "la dignidad humana es inviolable. Será respetada y protegida". De donde se entiende que la dignidad humana forma parte de la esencia de los derechos consignados en la Carta.

Asimismo, la Declaración Americana de los Derechos y Deberes del Hombre (1948) establece en su preámbulo que "todos los hombres nacen libres e iguales en dignidad y derechos" ${ }^{\prime 2}$. Igualmente, la Convención Americana sobre Derechos Humanos (1969) consagra también el principio de la dignidad de la persona humana, primero, en relación directa con el derecho a la integridad física y psíquica de la persona y, luego, vinculándolo con los derechos a la intimidad y al honor.

En el plano nacional, el respeto a la dignidad de la persona humana constituye el principio de base del ordenamiento jurídico en su conjunto. El texto de la Constitución Política del Perú (1993) se inicia proclamando, en su artículo primero, que "la defensa de la persona humana y el respeto de su dignidad son el fin supremo de la sociedad y del Estado" 6 . Ha sido también erigido en un principio fundamental

3 Convenio para la protección de los derechos humanos y la dignidad del ser humano con respecto a las aplicaciones de la biología y la medicina.

4 Vigente desde 1999.

5 Lamentablemente, en la misma declaración, el concepto de dignidad aparece vinculado al concepto de propiedad.

6 Artículos 1, 2 y 7 de la Constitución Política del Perú de 1993. En esa misma dirección, la Constitución Política de 1979, luego de precisar en su preámbulo la primacía y la dignidad de la persona humana, consagra en el artículo primero 
por la Ley General de Salud (1997), cuyo artículo 15.3 literal a) ${ }^{7}$ establece expresamente que toda persona tiene derecho "a ser atendida con pleno respeto a su dignidad [cursivas añadidas] e intimidad sin discriminación por acción u omisión de ningún tipo". Esto significa que el paciente, antes de ser un enfermo, es un sujeto de derecho.

Particularmente, en el dominio de la medicina y la biología (Monge, 2009, p. 235), el reconocimiento de la dignidad humana del paciente ha desencadenado la consagración de un "plexo" de deberes y derechos. Así se puede afirmar que la intervención médica practicada en ausencia de consentimiento del paciente y/o incumpliendo el deber de información que el médico debe brindarle antes de la intervención o tratamiento infringe el respeto que su dignidad humana exige.

$\mathrm{Al}$ respecto, cabe recordar que hasta hace algunas décadas correspondía al médico decidir unilateralmente el tratamiento o terapéutica que debía aplicarse al paciente. Una práctica socialmente aceptada le reconocía -sobre la base de sus conocimientos- la potestad de imponer, sin necesidad de explicación, aquello que a su ilustrado entender era bueno o conveniente para la salud del enfermo. El médico no estaba obligado a tomar en consideración la voluntad del paciente; este último -carente de todo conocimiento científico- no tenía el derecho a decidir ni a expresar sus preferencias sobre el devenir de su salud y hasta de su propia vida.

Hoy se puede decir que la relación paternalista médico-paciente ha dado un viraje sin precedentes en la historia de la medicina. Existe un claro e incuestionable consenso en el hecho de que la voluntad del enfermo debe ser respetada. Antes de que se le realice la intervención médica, es decir, previamente a cualquier acto médico específico, el paciente debe manifestar su asentimiento libre e informado. Naturalmente, esta exigencia difiere del consentimiento necesario para la celebración del contrato.

Es tan importante que se respete la potestad del paciente de tomar decisiones respecto a su salud ${ }^{8}$ que su consentimiento informado es la

que "la persona humana es el fin supremo de la sociedad y del Estado. Todos tienen la obligación de respetarla y protegerla".

7 Ley que establece los derechos de las personas usuarias de los servicios de salud. Ley 29414, 30 de setiembre de 2009, que modifica la Ley General de Salud de 1997.

8 Excepto aquellos casos de urgencia, donde existe un peligro inminente para la vida o la salud del paciente que se encuentra en estado de inconsciencia. 
condición sine qua non para calificar de lícita la intervención médica. Siendo así, conviene interrogarse sobre el fundamento teórico que justifica esta exigencia.

La necesidad del consentimiento libre e informado del paciente se deriva del principio de orden público y de alcance universal que establece que el cuerpo humano es inviolable (noli me tangere). La idea engloba la prohibición de dañar la integridad física y psíquica de la persona. Sin embargo, el principio no es absoluto, pues ciertas transgresiones a la integridad corporal son justificadas, si responden a una finalidad terapéutica y si reposan sobre el consentimiento libre e informado de la persona.

El principio adquiere singular trascendencia en el área médica, pues significa, por un lado, que el médico está autorizado a intervenir únicamente para alcanzar una finalidad terapéutica y previo cumplimiento de la citada condición. Quiere decir, por otro lado, que en su ausencia el gesto médico traspasa las fronteras que delimitan la licitud del ejercicio profesional, porque vulnera la libertad de la persona y consiguientemente transgrede la obligación de respetar la dignidad humana del paciente. En efecto, el principio del respeto de la dignidad del ser humano se presenta como el referente ético y jurídico mayor en la materia.

\section{El respeto de la dignidad del ser humano impide su instrumentalización}

En lo que concierne a la actividad médica, el principio del respeto de la dignidad del ser humano -en cuanto principio ético y jurídico directordelimita las fronteras entre aquello que está permitido y aquello que no lo está. Así, las diversas aplicaciones con carácter negativo que se desprenden del principio de la dignidad del ser humano son las siguientes: la prohibición de cualquier tratamiento o intervención médica al margen del consentimiento informado del paciente; la prohibición de experimentaciones sin consentimiento9; la prohibición de la venta de órganos, de gametos o de embriones; la prohibición de la clonación reproductiva

9 Cuando la ciencia coloca al ser humano como objeto de experimentación, obvia la singularidad inherente a cada ser humano y lo instrumentaliza. 
humana ${ }^{10}$, entre otras ${ }^{11}$. La dignidad del ser humano recusa esos comportamientos porque rebajan el sujeto a la calidad de objeto.

Correlativamente, la dignidad se plasma en diversos derechos inherentes al ser humano, entre ellos, el derecho a la vida, el derecho al respeto del cuerpo humano (derecho a la integridad del cuerpo) y el derecho al respeto de la libertad individual (autonomía de la persona). Se trata de derechos no solamente inherentes al ser humano, sino que además son catalogados como derechos irrenunciables.

Específicamente, la autonomía del paciente se identifica con la libertad individual de la persona de tomar sus propias decisiones (autodeterminación). Y el respeto de esa libertad individual, que sin llegar a convertirse en un principio absoluto, es el que se ubica en el eje de la decisión médica. En efecto, el respeto de la voluntad manifestada por el paciente implica el reconocimiento de su calidad de sujeto de derecho. Contrario sensu, el desconocimiento del consentimiento libre e informado hace tabla rasa de la autodeterminación o libertad la persona del paciente de tomar las decisiones relativas a su cuerpo y a su salud. Consecuentemente, lo despoja de su dignidad y lo degrada a la condición de objeto.

\section{La obligación de información que incumbe al médico}

La obligación de información que corresponde al médico fue afirmada, en el plano internacional, en la Declaración de Helsinki (1964) ${ }^{12}$ y en la Declaración de Tokio (1975) ${ }^{13}$. Engloba la explicación -que el facultativo debe al paciente- sobre su estado de salud, los exámenes a los que debe

10 Pretender predeterminar las características genéticas de un ser humano, según los intereses o deseos de otras personas, vulnera el derecho del individuo a su identidad genética propia y lo convierte en una cosa; es decir, lo instrumentaliza.

11 La prohibición de la esterilización sin consentimiento, la prohibición de la tortura, la prohibición de la esclavitud y del trabajo forzado, la prohibición de la trata de seres humanos.

12 La Declaración de Helsinki, promulgada por la Asociación Médica Mundial (WMA), contiene un conjunto de principios éticos que deben guiar la experimentación con seres humanos. Carece de carácter vinculante, pero es considerada por muchos como el documento más importante en este campo.

13 Normas directivas para médicos con respecto a la tortura y otros tratos o castigos crueles, inhumanos o degradantes, impuestos sobre personas detenidas o encarceladas. Fue adoptada por la 29. a Asamblea Médica Mundial, Tokio, Japón, octubre de 1975. 
someterse y las alternativas terapéuticas existentes, así como sus efectos. Comprende también la explicación sobre la evolución previsible de la enfermedad y su tratamiento, además de la información sobre los riesgos y beneficios esperados, entre otros. Esta obligación debe cumplirse previamente a la intervención médica, y no en el curso de la ejecución del acto terapéutico. En realidad, el paciente no puede asentir antes de haber recibido una información completa, objetiva, clara, precisa, adaptada a sus necesidades y a su nivel sociocultural. En suma, el paciente decide una vez que el médico haya satisfecho su derecho a saber.

En ese sentido, el artículo 27 de la Ley General de Salud (1997) prevé que "el médico tratante, así como el cirujano-dentista y la obstetra, están obligados a informar al paciente [cursivas añadidas] sobre el diagnóstico, pronóstico, tratamiento y manejo de su problema de salud, así como sobre los riesgos y consecuencias de los mismos".

Es evidente que, para que el consentimiento del paciente sea informado, debe disponer de un conjunto de datos que le permitan formarse una real y pertinente apreciación de su salud, de su evolución y de las consecuencias, riesgos y ventajas de la intervención a la cual se somete. Así, es posible afirmar que la responsabilidad del médico (Monge, 2010, p. 57) se encuentra comprometida a partir del solo hecho de la ausencia o insuficiente información relativa al diagnóstico, pronóstico, tratamiento, riesgos y consecuencias de los mismos.

Si bien existe consenso sobre el deber del profesional de la salud de informar al paciente -obligación que, por otra parte, es de carácter intuito personae-, múltiples preguntas rodean la ejecución misma de la obligación en vista de la obtención del consentimiento informado: ¿cómo debe cumplirse el deber de información?, ¿qué debe contener la información que el médico tiene que dar al paciente?, ¿cuál es la extensión del deber de información?

\section{1 ¿Cómo debe cumplirse el deber de información?}

En principio, corresponde al profesional de la salud velar siempre para que el mensaje sea bien entendido por el destinatario. La Ley General de Salud (1997) precisa, en el artículo 15, que toda persona tiene derecho:

f) A recibir en términos comprensibles información completa, oportuna y continuada sobre su enfermedad, incluyendo el diagnóstico, pronóstico y alternativas de tratamiento; así como sobre los riesgos, 
contraindicaciones, precauciones y advertencias de las intervenciones, tratamientos y medicamentos que se prescriban y administren.

En consecuencia, para que la información que el médico brinda al paciente adquiera las características de "comprensible", se entiende que debe tener las siguientes particularidades: objetiva, simple, accesible y leal. Quedan naturalmente excluidos los términos técnicos cuya comprensión no sea posible en consideración al nivel educativo y cultural del paciente.

El Código de Ética y Deontología del Colegio Médico del Perú (2007) establece, en el artículo 36, que es derecho del paciente el "obtener toda la información que sea veraz, oportuna, comprensible, acerca de su diagnóstico, tratamiento y pronóstico". El mismo cuerpo normativo enfatiza la obligación del profesional de la salud, indicando que le corresponde comprobar que la información ha sido entendida por el paciente y solamente entonces el consentimiento será considerado como manifestado con autonomía (Código de Ética y Deontología del Colegio Médico, 2007).

En el plano del derecho comparado, el Código de Deontología Médica Italiano, por ejemplo, establece que el médico debe proporcionar al paciente la información más adaptada al diagnóstico, el pronóstico, las perspectivas y las eventuales alternativas diagnósticas y terapéuticas, así como las consecuencias previsibles de las elecciones realizadas. De manera expresa, la legislación italiana precisa que, al proporcionar la información necesaria, el médico debe igualmente tener en cuenta la capacidad de comprensión del paciente. Es jurisprudencia constante en Italia que la información que el médico debe dar al paciente a fin de que su consentimiento sea realmente informado se refiere a los beneficios, las modalidades de intervención, la posibilidad eventual de elección entre diferentes técnicas, los riesgos previsibles, así como el alcance y las probabilidades de los resultados (Altavilla, 2008, p. 151).

En el plano europeo, el Convenio sobre los Derechos Humanos y la Biomedicina (1997), adoptado por los Estados miembros del Consejo de Europa, señala expresamente que la información que el médico debe brindar al paciente debe ser "adecuada [cursivas añadidas] acerca de la finalidad y la naturaleza de la intervención, así como sobre sus riesgos y consecuencias" 14 .

14 Artículo 5. 
En el mismo sentido, la Declaración Universal sobre Bioética y Derechos Humanos de la UNESCO (2005) precisa que "toda intervención médica preventiva, diagnóstica y terapéutica solo habrá de llevarse a cabo previo consentimiento libre e informado de la persona interesada, basado en la información adecuada [cursivas añadidas]".

Si esto es así, numerosas interrogantes surgen todavía respecto a la definición de los linderos de aquello que el médico está obligado a informar. Este aspecto adquiere relevancia en lo que se refiere a la prueba del cumplimiento o incumplimiento de la obligación.

\section{2 ¿Qué debe contener la información que el médico tiene que dar al paciente?}

Con relación al contenido mismo de la información, se plantea la pregunta de si el médico está obligado a decir y a explicar "todo" o debe transmitir solamente una información esencial. En realidad, el legislador coloca bajo la responsabilidad del facultativo un deber amplio de información. La Ley General de Salud (1997) establece en términos genéricos que la información que el médico debe al paciente debe ser completa, oportuna y continuada sobre su enfermedad, incluyendo el diagnóstico, pronóstico y alternativas de tratamiento.

Si el diagnóstico es entendido como el acto por el cual el médico identifica la enfermedad o establece los riesgos de que esta sobrevenga en función de las predisposiciones del paciente (Savatier, 2008, p. 26), se puede afirmar que la obligación que la ley pone bajo la responsabilidad del médico comprende también la comunicación de un diagnóstico o pronóstico desfavorable o fatal, aun cuando estime que el paciente no está en condiciones de afrontarlo. No obstante, es evidente que una comunicación de esa naturaleza podría afectar aún más la salud del paciente. En el extremo opuesto, se encuentra la hipótesis de un diagnóstico relativo a una enfermedad contagiosa; aquí el deseo del paciente de mantenerse en la ignorancia no puede, obviamente, ser respetado en función del riesgo de transmisión de la enfermedad ${ }^{15}$.

\section{3 ¿Cuál es la extensión del deber de información?}

Cuando la ley alude a la expresión "riesgos, contraindicaciones, precauciones y advertencias de las intervenciones, tratamientos y

15 Es lo que dispone el artículo L. 1111-2 del Código de la Salud Pública Francés. 
medicamentos que se prescriban y administren", ¿se refiere a los riesgos benignos o graves? ¿A los riesgos frecuentes o normalmente previsibles? ¿Corresponde al médico comunicar al paciente los riesgos excepcionales? La exigencia legislativa de que la información debe ser "completa, oportuna y continuada" significa que el médico debería informar todos los riesgos, incluidos aquellos excepcionales, aun cuando con ello corra el riesgo de perturbar emocionalmente al paciente ${ }^{16}$. De lo cual se colige que incurre en responsabilidad el médico que no informa al paciente (en forma completa) los riesgos de la intervención o que no solicita su consentimiento luego de haber brindado la referida información. El mismo análisis exige la hipótesis en la cual se establece que el paciente no se habría sometido al acto médico de haber sido pertinentemente informado respecto de los riesgos o complicaciones.

Así, algunos opinan que, aunque la obligación del médico se califique como "de medios", el facultativo se libera de su responsabilidad únicamente cuando informa al paciente de la gravedad o complejidad de su mal. Esa información es el elemento idóneo para la "distribución de riesgos" entre el facultativo y el paciente. Y es partiendo de la información y de la consiguiente distribución de los riesgos informados que el médico se compromete solo "hasta aquí" y no más. Agrega el argentino Mosset Iturraspe (2007) que "la muerte podría estar, en tales casos, fuera de los riesgos que el médico asume" (p. 151). Seguidamente el mismo autor afirma que "la falta de información, el aceptar el encargo sin detenerse a dar las explicaciones pertinentes, debe interpretarse como asunción lisa y llana de dificultades, riesgos y peligros" (p. 151). En efecto, la negligencia puede materializarse no por la falta de atención de las complicaciones ocurridas en la intervención, sino cuando la posibilidad de que ese riesgo sobrevenga no es puesto en conocimiento del paciente en forma previa a la operación.

Es el caso de un asunto examinado por el Tribunal de Defensa de la Competencia y de la Propiedad Intelectual (Indecopi), en el que durante una intervención quirúrgica destinada a extraer al paciente los gangliones que se habían formado en su mano izquierda, sufrió el corte

16 Algunos autores opinan que "solo se justifica ocultar al enfermo cierta información cuando su estado emocional o psíquico así lo aconsejen y el efecto de ella pueda resultar más perjudicial que beneficioso a la salud del asistido, o bien cuando se trate de pacientes con sus facultades mentales alteradas o sin capacidad jurídica para prestar válidamente su consentimiento (menores de edad)". 
de dos tendones, lo que perjudicó la movilidad de sus dedos. Si bien la afectación de los tendones constituye una complicación asociada a la intervención, Indecopi -sin aludir a la Ley General de Salud- resalta que el paciente "debió ser informado de dichos riesgos, pues resultaban relevantes para determinar su decisión de operarse o no". El mismo paciente había manifestado que, de haber conocido el riesgo, "hubiera optado por no someterse a la operación, ya que los gangliones a extraer no le causaban dolor". Es claro, como lo señala Indecopi, que la Autorización de Operación suscrita por el paciente no constituye prueba alguna de haber sido informado sobre los riesgos asociados a la extirpación de los gangliones ubicados en su mano izquierda, pues dicho documento solo es un formato que consigna en términos genéricos la siguiente frase: "[...] acepto los riesgos que de ella(s) pueda(n) originarse, así como las posibles secuelas de las que he sido debidamente informado" (Resolución 0295-2004/TDC-INDECOPI).

En el derecho quebequés, la extensión del deber de información relativo a los riesgos se mide no solamente con relación a la probabilidad estadística de su realización, sino también con respecto al impacto potencial de la realización del riesgo sobre el paciente. Se admite, a la vez, la frecuencia de su realización y la severidad del atentado al paciente.

Si hay consenso sobre el hecho de que el médico debe informar al paciente los riesgos previsibles, cuando se trata de intervenciones médicas que carecen de finalidad terapéutica -debido fundamentalmente a que su realización no es urgente ni necesaria-, la información respecto a los riesgos y sus consecuencias adquiere ciertas particularidades. En esta hipótesis, existe una fuerte tendencia, dentro de la jurisprudencia y legislación francesa, por ejemplo, a abandonar la distinción entre riesgos excepcionales y riesgos previsibles.

En nuestro medio, se debería igualmente colocar, en forma expresa, bajo la responsabilidad del cirujano plástico una obligación amplia de información (Monge, 2002, p. 8). Tendría que precisarse que incurre en responsabilidad si no informa al paciente no solamente de los riesgos normalmente previsibles, sino también de los riesgos excepcionales y los riesgos raros. Obviamente, estaría obligado a evocar el riesgo de complicaciones, de cicatrices inevitables, de secuelas inhabituales y la posibilidad de efectos traumáticos para que el propio paciente pueda sopesar las ventajas y los inconvenientes de la operación, el resultado estético anhelado y el riesgo al cual se somete. El cirujano plástico debe- 
ría ser sometido a un "verdadero deber de consejo y de precaución" (Tourneau y Cadiet, 1996, p. 286).

Así pues, incurre en responsabilidad el cirujano plástico que no informa al paciente el riesgo de la pérdida del ojo a consecuencia de una intervención dirigida a suprimir las arrugas. Debe también informar el riesgo de fracaso de la intervención o del tratamiento. En ese sentido, se admite que el incumplimiento del deber de información debe ser apreciado de manera más rigurosa (Lambert-Faivre, 1996, p. 664).

En un asunto ventilado ante la jurisdicción administrativa francesa, la paciente, que presentaba cicatrices luego de una intervención de cirugía estética, reprochaba al médico el hecho de no haberle informado previamente a la intervención de la existencia de ese riesgo. El Consejo de Estado Francés precisa que, en materia de cirugía estética, corresponde al médico una obligación particularmente amplia (de información) respecto a su paciente.

Esta tendencia ha sido consagrada a nivel legislativo, el Code de la Santé Publique francés prevé específicamente que, en el caso de prestaciones de cirugía estética, la obligación del médico de informar al paciente comprende no solamente las condiciones de la intervención, sino también los riesgos y las eventuales consecuencias y complicaciones que podrían derivarse. Paralelamente, establece la obligación de respetar un plazo mínimo o período de reflexión antes de la eventual intervención ${ }^{17}$ (Ley 2002-303).

Una esclarecedora sentencia de la Courd'Apel de París ${ }^{18}$ vincula explícitamente el deber de información a una obligación de abstención cada vez que esta condición no se cumple. Los magistrados señalan que corresponde al cirujano estético actuar con prudencia y diligencia, abs-

17 Code de la Santé Publique, article L6322-2: “Pour toute prestation de chirurgie esthétique, la personne concernée, et, s'il y a lieu, son représentant légal, doivent être informés par le praticien responsable des conditions de l'intervention, des risques et des éventuelles conséquences et complications. Cette information est accompagnée de la remise d'un devis détaillé. Un délai minimum doit être respecté par le praticien entre la remise de ce devis et l'intervention éventuelle. Pendant cette période, il ne peut être exigé ou obtenu de la personne concernée une contrepartie quelconque ni aucun engagement à l'exception des honoraires afférents aux consultations préalables à l'intervention" (Ley N. ${ }^{\circ}$ 2002-303 du 4 mars 2002. 5 mars 2002. Loi relative aux droits des malades et à la qualité du système de santé. Journal Officiel).

18 Courd'Apel de París, 16 de junio de 1995. 
teniéndose de hacer correr a su cliente un riesgo sin proporción a las ventajas esperadas. El médico debe informar "no solamente el alea inherente a la intervención y las secuelas que podrían derivarse [...], sino también negarse categóricamente a operar cuando haya desproporción manifiesta entre los riesgos y los resultados aleatorios esperados" (como se citó en Monge, 2012, p. 15).

De donde se deduce, como analiza pertinentemente la profesora Geneviève Viney (1996), que la obligación de información en las intervenciones sin finalidad terapéutica no busca lograr la aceptación del riesgo por el paciente, sino más bien llevarlo a renunciar a correr ese riesgo en los casos en los cuales las ventajas esperadas no son evidentemente superiores a los posibles inconvenientes.

\section{El paciente, previamente informado, tiene derecho a consentir la realización del acto médico}

El consentimiento del paciente al acto médico, cuyo presupuesto es la información brindada por el facultativo, traduce la expresión de la libertad fundamental de la persona de decidir, con autonomía, el devenir de su cuerpo y de su salud, cualquiera que sea el proceso patológico que le afecta. La idea es que el profesional sanitario no impone autoritariamente, sino que más bien propone el procedimiento terapéutico. Correlativamente, corresponde al paciente-como lo prescribe el Código de Ética y Deontología del Colegio Médico (2007) ${ }^{19}$ - el derecho de aceptarlo o rechazarlo.

Ese consentimiento comprende, por una parte, el acto quirúrgico y, por otra parte, la ejecución de una terapéutica determinada. La Ley General de Salud (1997) prevé, con carácter imperativo, que "ninguna persona [cursivas añadidas] puede ser sometida a tratamiento médico o quirúrgico, sin su consentimiento previo [cursivas añadidas] o el de la persona llamada legalmente a darlo, si correspondiere o estuviere impedida de hacerlo" 20 . La necesidad de contar con el acuerdo antelado del enfermo es ratificada por el artículo 15.4 de la misma ley, al consagrar que "toda persona tiene derecho [cursivas añadidas]: a) A otorgar su consen-

19 Artículo 63, literal e).- Aceptar o rechazar un procedimiento o tratamiento después de haber sido adecuadamente informado o a revocar su decisión en cualquier momento, sin obligación de expresión de causa.

20 Artículo 4. 
timiento [cursivas añadidas] informado, libre y voluntario, sin que medie ningún mecanismo que vicie su voluntad, para el procedimiento o tratamiento de salud"21 (Ley General de la Salud, 1997).

Ello consiste en que el médico informa completa y claramente al paciente sobre el procedimiento que va a realizar, comprueba que la información ha sido entendida por este $y$, solamente entonces, el paciente asentirá con autonomía. La conformidad manifestada por el paciente debe, naturalmente, ser expresa y revestir los caracteres de libre, voluntaria y consciente ${ }^{22}$; es decir, exenta de vicios, error, dolo o violencia. El principio encuentra su fuente en el respeto a los derechos fundamentales de la persona, en el respeto de su derecho a la libertad, en el respeto de la integridad de su propio cuerpo (noli me tangere) y, finalmente, en el respeto de la dignidad de la persona humana, en cuanto fin supremo de la sociedad y del Estado.

Es de advertir, obviamente, que la facultad de consentir o negarse a la intervención médica recae, a título personal, en el mismo paciente. La única excepción es el caso en el cual el enfermo no está en capacidad de expresar su voluntad (pacientes inconscientes o psiquiátricos), unido a una urgencia o a la existencia de un peligro inminente para su vida o su salud. Y aun allí el médico debe proceder con previa información y aquiescencia de sus parientes, salvo urgencia y/o imposibilidad material de consultar a los mismos ${ }^{23}$.

21 La obligación de contar con el acuerdo del paciente está contemplada igualmente en el Código de Ética y Deontología del Colegio Médico del Perú. Este último establece que "las intervenciones quirúrgicas requieren del consentimiento informado escrito, salvo en situación de emergencia" (artículo 62).

22 Así lo precisa una esclarecedora norma técnica del Sector Salud, cuando señala que el consentimiento informado "es la conformidad expresa del paciente o de su representante legal cuando el paciente está imposibilitado, con respecto a una atención médica, quirúrgica o algún otro procedimiento, en forma libre, voluntaria y consciente, después que el médico u otro profesional de la salud competente le ha informado de la naturaleza de la atención, incluyendo los riesgos reales y potenciales, efectos colaterales y efectos adversos, así como los beneficios, lo cual debe ser registrado y firmado en un documento, por el paciente o su representante legal y el profesional responsable" (Norma Técnica N.o 022-MINSA/ DGSP-V.02. Dirección General de Salud de las Personas, Norma Técnica de la Historia Clínica de los Establecimientos del Sector Salud, Lima, 2005).

23 La Norma Técnica N. ${ }^{\circ}$ 022-MINSA/DGSP-V.02 precisa expresamente que "se exceptúa de consentimiento informado en caso de situación de emergencia, según Ley General de Salud, artículos 4 y 40". 
Paralelamente, la manifestación de voluntad del paciente debe ser expresa. La ley rodea el consentimiento de un carácter solemne, en atención a la naturaleza o la gravedad de la intervención, cuando la misma es susceptible de afectar física o psíquicamente al paciente. Así, la Ley General de Salud (1997) prevé en el segundo párrafo del artículo 27 que "para aplicar tratamientos especiales, realizar pruebas riesgosas o practicar intervenciones que puedan afectar psíquica o físicamente al paciente, el médico está obligado a obtener por escrito su consentimiento informado [cursivas añadidas]". El artículo 15.4 reitera:

a.2) Cuando se trate de pruebas riesgosas, intervenciones quirúrgicas, anticoncepción quirúrgica o procedimientos que puedan afectar la integridad de la persona, supuesto en el cual el consentimiento informado debe constar por escrito [cursivas añadidas] en un documento oficial que visibilice el proceso de información y decisión. (Ley General de Salud, 1997).

Fuera de esas hipótesis, al menos formalmente, la firma de un documento escrito no es exigida ad validitatem. Por el contrario, en otros países, como por ejemplo, en Estados Unidos, el consentimiento del paciente debe siempre revestir un formalismo específico. Tradicionalmente, en este país todo acto médico, toda prescripción y toda terapéutica requieren el consentimiento escrito del paciente.

En la eventualidad de que el paciente se oponga al tratamiento, el médico no puede intervenir en contra de su voluntad, aun en los casos en los cuales media finalidad terapéutica. Aquí el rol del facultativo debe limitarse a informarle sobre las consecuencias que podrían derivarse de esa oposición. Así lo prevé la Ley General de Salud (1997) en el artículo 15.2 literal g), cuando señala que la persona tiene derecho:

A ser informada sobre su derecho a negarse a recibir o continuar el tratamiento y a que se le explique las consecuencias de esa negativa. La negativa a recibir el tratamiento puede expresarse anticipadamente, una vez conocido el plan terapéutico contra la enfermedad.

Consecuentemente, si en el curso de la intervención quirúrgica, se presenta la necesidad de realizar una operación diferente de aquella inicialmente prevista, el médico debería cesar el acto quirúrgico y practicar la nueva intervención solamente cuando haya obtenido el asentimiento del enfermo. Salvo, como se ha señalado antes, cuando medie un estado 
de necesidad o una situación de urgencia. Por ejemplo, cuando en el curso de una intervención se descubre una afección mucho más grave que aquella diagnosticada o una situación de verdadera urgencia terapéutica. Aquí, dado que el retardo puede redundar en perjuicio de la salud del paciente, el médico está autorizado a modificar o ampliar la operación prevista. Siendo así, en la actualidad, el consentimiento informado se convierte, como lo señala Fernández Sessarego (2011), en "un presupuesto y un integrante de la lexartis, pues sin la manifestación de voluntad previa del paciente es jurídica y éticamente imposible iniciar cualquier acto, tratamiento o intervención médica" (p. 235).

La exigencia del consentimiento informado del paciente antes de la realización de la intervención quirúrgica es plasmada en la Resolución 0763-2005/TDC de fecha 13 de julio de 2005, del Tribunal de Defensa de la Competencia y de la Propiedad Intelectual (Indecopi), en un asunto en el cual un paciente recurrió a una clínica local para ser intervenido quirúrgicamente de la próstata. Durante la operación, se le habría practicado además una hernioplastia, sin su autorización, la cual se complicó posteriormente y se derivó en una atrofia testicular y fibrosis en la zona inguinal ${ }^{24}$. Este hecho determinó que se le practicara, dos meses después, una orquiectomía derecha, nuevamente sin su conocimiento ni consentimiento.

$\mathrm{Al}$ parecer, momentos antes de esta segunda intervención y cuando el paciente se encontraba ya bajo los efectos de la anestesia, la clínica habría obtenido el consentimiento de su esposa. Sin embargo, no consta que ese consentimiento fuera informado, pues la esposa "no tenía conocimiento de que estaba autorizando la extirpación del testículo derecho". La resolución resalta de manera pertinente que la ausencia de consentimiento expreso del paciente, entre otros, pone en evidencia la negligencia con la que actuaron los médicos ${ }^{25}$ y concluye señalando que la clínica en cuestión "no brindó un servicio idóneo al denunciante, de acuerdo con lo dispuesto en el artículo 8 de la Ley de Protección al Consumidor" (Resolución 0763-2005/TDC-INDECOPI, 2005).

24 Complicación, al parecer previsible, en este tipo de intervenciones.

25 Para la resolución de Indecopi, “el efecto más grave de la conducta de la Clínica [...] ha repercutido en la salud del denunciante, puesto que ha sufrido la pérdida de su testículo derecho, con las consecuentes limitaciones físicas y psicológicas que ello le representa, el comprensible daño a su autoestima y las repercusiones que ello ha tenido en su vida familiar, a las cuales ha hecho mención a lo largo del procedimiento". 
Contrariamente, en el estado actual de la legislación resulta -por decir lo menos- incomprensible que la Corte Superior de Lima ignore simplemente las normas antes citadas y se atreva a afirmar en resolución emitida el 22 de agosto de 2001 lo siguiente:

No es suficiente para acreditar el dolo; y en todo caso, la culpa inexcusable, que la demandada no haya obtenido permiso de la actora o algún familiar de esta para realizar la intervención quirúrgica -implante de piedra pómez-, por cuanto, dado el tipo de operación, resulta inverosímil que la actora hay desconocido

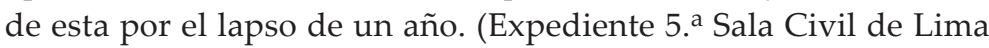
N. o 97-62552-130, 2001)

En el presente caso, la demandante exigía la indemnización correspondiente por el daño moral producido a consecuencia de la pérdida total de la visión del ojo izquierdo, lo que le había causado "un estado de sufrimiento y de dolor permanente en menoscabo de su integridad emocional y sociológica [sic]".

Consta en la referida resolución que la paciente recurrió al Instituto Nacional del Ojo (INO), donde fue atendida por la médica demandada por el diagnóstico "secuela de uveítis en el ojo izquierdo, uveítis anterior crónica granulomatosa"; se señala, asimismo, que fue sometida posteriormente a dos intervenciones quirúrgicas en el consultorio particular de la demandada, donde se le practicó "la evisceración del ojo izquierdo con una implantación de piedra pómez". Si bien es cierto que la paciente recibió tratamiento por un período de tiempo aproximado de dos años y que conocía su estado de salud, no se le puede atribuir a aquello el valor de una especie de adhesión implícita a ninguna intervención quirúrgica, menos aún si existe el riesgo de perder completamente la visión (Expediente 5. ${ }^{\text {ta }}$ Sala Civil de Lima N. ${ }^{\circ}$ 97-62552-130, 2001).

Siendo así, se puede afirmar que el acto médico realizado al margen del asentimiento del paciente configura un atentado ilícito a la integridad física del cuerpo humano. Contraría igualmente el principio que impone el respeto de la persona y de su dignidad. En el presente asunto, es evidente, además, que en función del riesgo de pérdida de la visión y de la consecuente afección psíquica que puede derivarse de la misma, era indispensable que el consentimiento conste por escrito, tal como lo prevé el artículo 27 de la Ley General de Salud (1997). 
En ausencia de consentimiento, el gesto médico constituye, como claramente se ha señalado, un atentado ilícito a la integridad del cuerpo humano que configura desde el punto de vista penal el delito de lesiones o lesiones seguidas de muerte, si fuera el caso. Desde la perspectiva civil, el médico incurre en responsabilidad civil y debe ser condenado a indemnizar al paciente por el daño sufrido.

Diversos ejemplos ilustran esta hipótesis. Es el caso del cirujano que en el curso de una intervención de cesárea procede simultáneamente, sin el conocimiento ni consentimiento de la paciente, a la ligadura de trompas en razón del riesgo que un nuevo embarazo puede representar para ella. Es jurisprudencia constante en diversos países que una intervención de esta naturaleza constituye "una elección estrictamente personal de la interesada". El mismo análisis requiere el caso del cirujano plástico que, sin advertir a su paciente, modifica en el curso de la intervención el lugar de extracción del pedazo de piel necesario para un trasplante, lo que da lugar a la deformación (hundimiento) de la totalidad de la fase interna de la pierna (Cours de Cassation, 1992) ${ }^{26}$.

Conviene recordar, finalmente, que para que el consentimiento sea válido (jurídicamente eficaz) es indispensable no solamente que la voluntad exista y sea manifestada, sino además que se funde en una voluntad real, libre y consciente. En efecto, la prestación de servicios médicos está sujeta a las condiciones de validez de todo contrato, lo cual exige que el paciente preste su asentimiento en conocimiento de causa; es decir, se requiere un consentimiento libre e informado que se obtendrá única y exclusivamente cuando el profesional de la salud cumpla, a su vez y previamente, con la obligación de información que le incumbe.

La obligación de informar y el derecho de consentir aparecen así como las dos caras de una misma medalla, cuyo fin último es garantizar el respeto de la dignidad humana del paciente.

\section{Referencias}

Altavilla, A. (2008). La responsabilité médicale en Italie: orientations actuelles et perspectives. En A.-M. Duguet, I. Filippi y J. Herveg (Eds.). Evolution récente des actions en responsabilité médicale en France.

26 Jurisprudencia francesa: Cours de Cassation, Bull. civ., I, 14 janvier 1992. 
Comparaison avec l'étranger (pp.151-162). París, Francia: Université Européenne d'été de droit de la santé et éthique médical.

Carta de los Derechos Universales de la Unión Europea. (2000). Diario Oficial de las Comunidades Europeas. Recuperado de http://www. europarl.europa.eu/charter/pdf/text_es.pdf

Código Civil (Francia). Loi contenant la réunion des lois civiles en un seul corps de lois. (21 de marzo de 1804). Madrid, España: Marcial Pons, Ediciones Jurídicas y Sociales.

Convención Americana sobre Derechos Humanos, Pacto de San José, suscrita en la conferencia especializada interamericana sobre Derechos Humanos (B-32). (1969). En Organización de los Estados Americanos [Página web]. Recuperado de http://www.oas.org/dil/ esp/tratados_B-32_Convencion_Americana_sobre_Derechos_ Humanos.htm

Código de Ética y Deontología del Colegio Médico. (2007). En Colegio Médico del Perú [Página web]. Recuperado de http://www.cmp. org.pe/doc_norm/codigo_etica_cmp_OCT-2007.pdf

Convenio sobre los Derechos Humanos y la Biomedicina. (1997). Agencia Estatal. Boletín Oficial del Estado del Gobierno de España. Recuperado de https://www.boe.es/buscar/doc.php?id=BOE-A-1999-20638

Constitución Política del Perú. (1993). En Congreso de la República del Perú [Página web]. Recuperado de http://www4.congreso.gob.pe/ ntley/Imagenes/Constitu/Cons1993.pdf

Cours de Cassation. (14 de enero de 1992). Jurisprudencia francesa. Bull. civ. I.

Declaración Americana de los Derechos y Deberes del Hombre. (1948). En Organización de los Estados Americanos [Página web]. Recuperadodehttps://www.oas.org/dil/esp/Declaraci\%C3\%B3n_ Americana_e_los_Derechos_y_Deberes_del_Hombre_1948.pdf

Declaración de Helsinki de la Asociación Médica Mundial. (1964). En World Medical Association [Página web]. Recuperado de http:// www.wma.net/es/30publications/10policies/b3/17c_es.pdf

Declaración de Tokio. (1975). En World Medical Association [Página web]. Recuperado de http://www.wma.net/es/30publications/10policies/c18/ 
Declaración Universal sobre el Genoma Humano y los Derechos Humanos, aprobada por la Conferencia General de la UNESCO. (1997). En Organización de las Naciones Unidas para la Educación, la Ciencia y la Cultura [Página web]. Recuperado de http://portal.unesco. org/es/ev.php-URL_ID=13177\&URL_DO=DO_TOPIC\&URL_ SECTION=201.html

Declaración Universal sobre Bioética y Derechos Humanos de la UNESCO, aprobada por la Conferencia General de la UNESCO. (2005). En Organización de las Naciones Unidas para la Educación, la Ciencia y la Cultura [Página web]. Recuperado de http://portal.unesco. org/es/ev.php-URL_ID=31058\&URL_DO=DO_TOPIC\&URL_ SECTION=201.html

Edelman, B. (1997). La dignité de la personne humaine, un concept nouveau. París, Francia: Recueil Dalloz 1.

Expediente N. ${ }^{o}$ 97-62552-130. (22 de agosto de 2001). (Lima). 5. ${ }^{\text {ta }}$ Sala Civil de la Corte Superior de Lima.

Fernández Sessarego, C. (2011). La responsabilidad civil del médico y el consentimiento informado. Lima, Perú: Motivensa, Editora Jurídica.

Habermas, J. (2010). El concepto de dignidad humana y la utopía realista de los derechos humanos. Diánoia, 55(64), 3-25.

Lambert-Faivre, Y. (1996). Droit du dommage corporel. Systèmes d'indemnisation. París, Francia: Dalloz.

Landa, C. (2002). Dignidad de la persona humana. Cuestiones Constitucionales. Revista Mexicana de Derecho Constitucional, 7, 109-138.

Ley fundamental de Alemania. (1949). Recuperado de https://www. btg-bestellservice.de/pdf/80206000.pdf

Ley 26842. Ley General de Salud. (9 de julio de 1997). En Ministerio de Salud del Perú [Página web]. Recuperado de http://www.minsa. gob.pe/renhice/documentos/normativa/Ley\%2026842-1997\%20 -\%20Ley\%20General\%20de\%20Salud\%20Concordada.pdf

Ley N.o 2002-303 du 4 mars 2002. (5 de marzo de 2002). Loi relative aux droits des malades et à la qualité du système de santé. Journal Officiel.

Mosset Iturraspe, J. (2007). De la imputación subjetiva a la objetiva (en la responsabilidad por incumplimiento contractual). En A. Kemelmajer De Carlucci (Dir.). Responsabilidad Civil. Buenos Aires, Argentina: Rubinzal-Culzoni Editores. 
Monge, L. (2012). ¿El nacimiento no deseado podría constituir un daño indemnizable? (Diagnóstico prenatal fallido y responsabilidad médica en la jurisprudencia francesa). Ius et Praxis, 0(43), 15-45.

Monge, L. (2010). Responsabilidad civil de los médicos: aplicación de los artículos 1970 y 1762 del Código Civil: ¿acierto o despropósito? Revista del Foro. Colegio de Abogados de Lima, 95, 57-62.

Monge, L. (2009). Los desafíos de la revolución biomédica en el vigésimo quinto aniversario del Código Civil. Revista Athina, 7, 235.

Monge, L. (2002). Responsabilidad civil de los cirujanos plásticos. Legal Express. Gaceta Jurídica, 23, 8.

Pérez de Leal, R. (1995). Responsabilidad civil del médico. Tendencias clásicas y modernas. Buenos Aires, Argentina: Universidad.

Preámbulo de la Declaración Universal de los Derechos Humanos. (1948). En Naciones Unidas [Página web]. Recuperado de http:// www.un.org/es/documents/udhr/index_print.shtml

Resolución N. ${ }^{\circ}$ 0763-2005/TDC-INDECOPI. Expediente N. ${ }^{\circ}$ 852-2003/ CPC. Sala de Defensa de la Competencia.

Resolución N. ${ }^{o}$ 0295-2004/TDC-INDECOPI. Tribunal de Defensa de la Competencia y de la Propiedad Intelectual (Indecopi).

Savatier, E. (2008). Responsabilité civile et assurance. París, Francia: Juris-classeur.

Seriaux, A. (1997). La dignité humaine, principe universel du droit? Actaphilosophica, 6, 289-301.

Tourneau, P., y Cadiet, L. (1996). Droit de la responsabilité. París, Francia: Dalloz.

Verspieren, P. (2014). La dignité de la personne humaine. Recuperado de http://ccsd11.ccsd.cnrs.fr/?q=node/1937

Viney, G. (1996). Responsabilité Civile. JCP. Chr. 3985. 
